SÍNTESF. - REV. DF FIIOSOHA

v. 27 N. 89 (2000): $413-418$

\title{
MOUNIER E O PERSONALISMO
}

Alino Lorenzon

$U G F$

Emmanuel Mounier, Écrits sur le personnalisme, Préface de Paul Ricoeur, Paris: Seuil, 2000. 396 p. (Essais, 412).

obra faz parte do programa editorial de textos de ou sobre E.
Mounier, pela passagem do $50^{\circ}$ aniversário de seu falecimen-
to. O prefácio de Paul Ricoeur, amigo e discípulo de Mounier,
e colaborador permanente da revista Esprit, situa muito bem o projeto
e a intenção de um dos principais teóricos do personalismo. Ricoeur
concentra sua argumentação em torno da pessoa, na sua totalidade,
individual e comunitária. E se a categoria de pessoa hoje é retomada
com tanto vigor, sobretudo nas esferas dos direitos humanos, da eco-
nomia, da política, da bioética, do direito, das ciências biomédicas e do
meio ambiente, significa para o pensador um apelo. Parece que a ca-
tegoria de pessoa possui um poder evocador e de compromisso muito
mais forte do que as de consciência, sujeito, étu, indivíduo e outras. A
consciência, após a revolução freudiana, não possui mais aquela sobe-
rania e transparência, atribuídas, sobretudo a partir de Descartes. O
sujeito, com a crítica das ideologias e da Escola de Frankfurt, também
revelou uma certa ilusão filosófica. O eu se ressentiu de um certo
solipsismo teórico, e a filosofia do outro, como a de Emmanuel Lévinas,
mostrou sua impotência de pensar de modo isolado. Quanto ao indi- 
'idtu, conhecemos muito bem seus percalços, sem falar na absolutização do individualismo. Em seguida, Ricoeur, a partir de Mounier e de Éric Weil, lembra o estatuto epistemológico da pessoa como atitude, ou melhor, "uma espécie de demonstração, mas não de demonstração" (p. 11). Mas Ricoeur julga ainda mais adequado empregar a expressão atitude-pessoa, porquanto ela supõe um engajamento na crise em que nos encontramos permanentemente no tempo. A crise que aparece em todos os campos da atividade humana.

O prefácio de Ricoeur é muito denso. Merece uma leitura aprofundada, porquanto apenas algumas de suas reflexões aqui aparecem filtradas pelo leitor.

Guy Coq, autor da escolha dos três textos que compõem a obra, os selecionou numa perspectiva de unidade temática, o personalismo. Quanto ao emprego desse ismo, Mounier nos adverte que se recusa classificá-lo como mais um sistema, ao lado dos existencialismos, marxismos e tantos outros, e muito menos como "uma máquina política". O termo foi simplesmente utilizado por Mounier "para designar uma certa perspectiva dos problemas humanos, e para acentuar, na solução da crise do século $X X$, certas exigência que nem sempre são postas em valor". O personalismo não se apresenta para encobrir uma certa preguiça intelectual ou para defender formas de civilização que a história condena. "Desejo que estas páginas ajudem a pensar e a criar, e a não se proteger contra os apelos do mundo".

O livro reúne três textos: 1 - Manifesto a serviço do personalismo; 2 - Anarquia e personalismo; 3 - O que é o personalismo?

Nossa intenção consistirá apenas em dar um apanhado informativo muito sintético, despertando no leitor o interesse e a motivação para uma leitura meditada e criativa.

\section{I - Manifesto a serviço do personalismo}

Publicado pela primeira vez na França em 1936, foi traduzido em Portugal em 1967 pela livraria Moraes de Lisboa.

Foi com bastante hesitações que Mounier intitulou seu trabalho de Manifesto, mas o fez como um apelo aos verdadeiros jovens para a invenção e ao não conformismo, porquanto o Manifesto não poderia se constituir num "substituto do pensamento ou da ação". E quanto ao personalismo, o próprio Mounier adianta uma rápida formulação explicativa. 
"Chamamos personalista toda doutrina, toda civilização que afirma o primado da pessoa humana sobre as necessidades materiais e sobre os aparelhos coletivos que sustentam seu desenvolvimento" (p. 20). O personalismo não anuncia mais uma escola, ou um sistema fechado, mas reúne elementos de ordem metafísica, material, moral e espiritual que possibilitem fundar e fundamentar uma civilizaçào devotada à pessoa humana em todas as suas dimensões.

Inicialmente, Mounier traça um diagnóstico do "mundo moderno contra a pessoa", impregnado por uma civilizaçào burguesa $\mathrm{e}$ individualista, ameaçado pelo fascismo e marxismo coletivista. Opóe-lhe então os "Princípios de uma civilização personalista", que teria como base a dupla pesson e' comnlinitade, à qual Paul Ricoeur acrescentará a expressão muito significativa de "em instituições justas" (V. Sot-mèmllt comme un altrit, pp. 227-236).

Estabelecendo de início uma distinção entre indivíduo e pessoa, Mounier lembra as características desta, como a incarnação e o engajamento, a

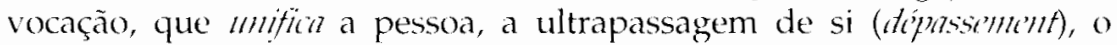
despojamento (d'́puillement), a liberdade e a autonomia, a comunhào e a comunidade. E, ao falar de uma civilização comunitária, alerta-nos para o fato de que "o primeiro ato de minha iniciação à vida pessoal é a tomada de consciência da minha vida anônima" (p. 82).

Mas, voltando aos vários graus de comunidade, caracteriza o mais elementar como o das societndes c'm mís outros, como um "público", um partido, uma sociedade qualquer. Uma outra forma mais viva de sociedade em nós se encontra na camaradagem e companhlorismo. Vêm depois as soctidutes aitnis, como uma família, uma economia. As sociedtates dos espiritos, isto é, dos cientistas, dos acadêmicos, as sociedates jutridicas contrinturis. Essas e outras não constituiriam comuntidates no sentido de uma filosofia personalista. Mounier reserva então o nome de comunidade àquela que "mais do que simbolicamente seria uma pesson de pessods" (p. 85).

Ao estabelecer as estruturas-mestras de um regime personalista, visando uma concepção total da civilização, Mounier desenvolve os temas seguintes:

1. A educafino da pessea, que tem como "missão de despertar (ézeille") pessoas capazes de viver e de se engajar, como pessoa" (p. 97), de usar sua liberdade com responsabilidade. A educação da pessoa deve ser total, isto é, em todas as suas dimensöes.

2. A zitlo priouda, isto é, a pessoa precisa de uma interioridade e da meditação, que preparam para a vida pública. E aqui Mounier consagra espaços a temas específicos, como a mulher, a família, a criança e a família. Sob o título "A mulher também é uma pessoa", título dado 
a um longo dossiê publicado na revista Esprit em junho de 1936, representou naquele momento uma revolução, antecipando-se às vagas feministas da Europa. Em "Da família celular à família comunitária", Mounier nos adverte para os riscos que pode correr a família chamada celular, se não se abrir à grande família humana (comunitária). E aqui entram a posição e a dignidade da mulher casada e da pessoa dos filhos, lembrando por fim que "a família é uma comunidade natural de pessoa" (p. 12).

3. A cultura da pessoa. Após haver desenvolvido uma crítica à cultura burguesa e à cultura dirigida, como ocorreu na Alemanha nazista e na Rússia comunista, e também nos grupos dominados pelo capital, Mounier traça algumas características de uma cultura personalista. A fonte da cultura está no povo, como o demonstram pelas suas obras Montaigne, Rabelais, Pascal e Péguy. Ademais, Mounier pensa que toda cultura possui esta exigência fundamental, metafísica e pessoal. Metafísica, a saber, o enriquecimento interior do sujeito, e não um simples acúmulo de saber-fazer ou de saber-dizer.

4. Una economia para a pessoa, porquanto nenhum problema humano pode ser resolvido ou mesmo definido numa pura técnica. A crítica de Mounier ao capitalismo mostra como ele tende "a se organizar inteiramente fora da pesson, sobre um fim quantitativo, impessoal e exclusivo: o lucro" (p. 140). E por diversas vezes alerta contra a fecundidade monstruosa do dinheiro. Revelador é o número especial de Esprit, consagrado ao tema: L'Argent, misère du pauvre, misère du riche, octobre 1933. Denuncia ao mesmo tempo o capital contra o trabalho, a liberdade e a responsabilidade contra o consumidor e a propriedade pessoal.

A esse tipo de economia opõe então os princípios de uma economia a serviço da pessoa, preconizando a primazia do trabalho sobre o capital, da responsabilidade pessoal sobre o aparelho anônimo, do serviço social sobre o proveito, e dos organismos sobre os mecanismos. E isso somente será possível numa economia e numa sociedade pluralistas.

5. A sociedade política. A vida política deveria ser reconstituída a partir e sobre organismos ou instâncias que realmente atendam à pessoa integral. E nesse sentido há toda uma aprendizagem que o homem precisa empreender para com a comunidade. Mounier se coloca na tradição que dá à política aquele sentido e aquela exigência do bem comum, e não de pessoas, de partidos, de grupos e faç̧ões. Em face à democracia liberal e parlamentar, bem como em face à democracia majoritária, mantém uma posição muito crítica, por repousarem sobre o postulado e sobre o mito da soberania popular. É que a representação política geralmente está eivada de profundas falhas, limites e distorções.

6. A sociedade internacional e inter-racial. Mounier propõe uma comunidade (e não uma sociedade) internacional orgânica, que não seria 
constituída pelos Estados soberanos, mas sim pelas comunidades vivas (viontes) de povos diretamente representados fora e ao lado dos Estados. Assim, o direito internacional teria como objeto não mais os Estados, mas sim as pessoas. Seria uma fórmula de proteção da pessoa contra o arbítrio dos estados.

Com respeito à comunidade internacional, Mounier se insurge sobretudo contra o colonialismo. Como um dos pioneiros de denúncia e combate desse flagelo, além da participação de apoio aos movimentos de descolonização, publica um número especial da revista Esfrit em dezembro de 1935. Citaremos apenas uma passagem do livro que estamos resenhando "Infelizmente, sob pretexto de exploração racional do globo, é o imperialismo capitalista que se tem precipitado sobre o trabalho barato, as matérias primas abundantes e os novos debouchés, para uma grande prosperidade do proveito, sem consideração para os direitos dos primeiros ocupantes" (pp. 194-195)

\section{II - Anarquia e personalismo}

Num texto muito denso, Mounier, como é de seu hábito de filosofar, estabelece um diálogo muito fecundo com os teóricos do anarquismo em torno de alguns temas por ele julgados relevantes na perspectiva do personalismo (pp. 213-307). Os pensadores mais citados são Proudhon, Bakounine e Kropotkine. Inicialmente, conceitua anarquia e anarquismo no sentido desses teóricos, para depois discutir os temas seguintes: o movimento operário, autoridade e poder, comparando-os com a doutrina personalista, povo e governo, do federalismo à cidade (no sentido dos gregos) pluralista, anarquismo e pessoa, busca (recherche) da comunidade e da liberdade. Quanto ao federalismo, na inspiração de Prouchon, Mounier e os grupos da revista e do movimento Esprit foram talvez os pioneiros em desenvolver discussões e propostas de concretização para a Europa.

\section{III - O que é personalismo?}

O texto foi publicado dez anos após $O$ manifesto a serriço do personalismo (1936). Foram dez anos de experiência e de reflexão. Novos problemas e novos desafios surgiram e era preciso dar-lhes um encaminhamento de resposta. Mounier insiste numa advertência já feita em vários trabalhos anteriores. "O "personalismo", enquanto depender de mim, jamais será um sistema nem uma máquina política. 
Empregamos esse termo cômodo para designar uma certa perspectiva dos problemas humanos, e para acentuar, na solução da crise do século $X X$, certas exigências que nem sempre são postas no devido valor" (p. 311). "Desejo que estas páginas ajudem a pensar e a criar (...)" (p. 312). Os temas tratados são os seguintes: o personalismo do engajamento, os direitos da transcendência, a crise do século $X X$, as duas alienações (individualismo e idealismo), no coração do materialismo, do coletivismo e do espiritualismo, os equívocos do personalismo como sistema, o verbalismo, o individualismo, o idealismo entre outros.

À guisa de conclusão, convém recordar o que disse Paul Ricoeur no prefácio, enfatizando a riqueza da relação pessoa e comunidade, bem como o diagnóstico da crise de civilização, que subjazem \às análises e à filosofia de Mounier, sua preocupação constante com o sentido e a mensagem do acontecimento (l'événement ser notre maitre intéricur, escreverá numa carta a Jean-Marie Domenach, seu sucessor na redação da revista Esprift). Mounier sempre teve o cuidado de articular seu pensamento e sua reflexão com o engajamento, isto é, com o compromisso de ser coerente consigo mesmo e com a realização de um mundo melhor e mais humano e de um cristianismo não identificado com o que ele chamou le désordre établi.

Endereço do Autor:

Rua Pereira da Silva, $586 / 701$

22221-140 Rio de Janeiro - RJ 